\title{
Anticyclonic eddies increase accumulation of microplastic in the North Atlantic subtropical gyre
}

\author{
Laurent Brach ${ }^{\mathrm{a}}$, Patrick Deixonne ${ }^{\mathrm{b}}$, Marie-France Bernard ${ }^{\mathrm{b}}$, Edmée Durand ${ }^{\mathrm{c}}$, \\ Marie-Christine Desjean ${ }^{\mathrm{d}}$, Emile Perez ${ }^{\mathrm{a}}$, Erik van Sebille ${ }^{\mathrm{e}, \mathrm{f}}$, Alexandra ter Halle ${ }^{\mathrm{a}, *}$ \\ ${ }^{a}$ Laboratoire des Interactions Moléculaires et Réactivité Chimique et Photochimique (IMRCP), UMR CNRS 5623, Université Paul Sabatier-UPS, Bâtiment 2R1, 3ème étage, \\ 118, route de Narbonne, 31062 Toulouse Cedex 09, France \\ b Expédition Septième Continent, Rue des Vanniers Domaine de Marie, 97224 Ducos, Martinique, France \\ ${ }^{\mathrm{c}}$ Mercator Océan, Parc Technologique du Canal, 8-10 rue Hermès, 31520 Ramonville Saint Agne, France \\ ${ }^{\mathrm{d}}$ Centre National d'Etudes Spatiales, 18 avenue Edouard Belin, 31401 Toulouse Cedex 4, France \\ e Grantham Institute \& Department of Physics, Imperial College London, SW7 2AZ London, United Kingdom \\ ${ }^{\mathrm{f}}$ Institute for Marine and Atmospheric research Utrecht, Utrecht University, 3584 CC, Netherlands
}

\section{A R T I C L E I N F O}

\section{Keywords:}

Microplastic

North Atlantic subtropical gyre

Marine litter

Sea level anomalies

Mesoscale eddies

Satellite observations

Oceanic current models

\begin{abstract}
A B S T R A C T
There are fundamental gaps in our understanding of the fates of microplastics in the ocean, which must be overcome if the severity of this pollution is to be fully assessed. The predominant pattern is high accumulation of microplastic in subtropical gyres. Using in situ measurements from the 7th Continent expedition in the North Atlantic subtropical gyre, data from satellite observations and models, we show how microplastic concentrations were up to 9.4 times higher in an anticyclonic eddy explored, compared to the cyclonic eddy. Although our sample size is small, this is the first suggestive evidence that mesoscale eddies might trap, concentrate and potentially transport microplastics. As eddies are known to congregate nutrients and organisms, this phenomenon should be considered with regards to the potential impact of plastic pollution on the ecosystem in the open ocean.
\end{abstract}

\section{Introduction}

Because of the durability of plastic and the constantly increasing inputs, plastic debris is accumulating in every environment. Plastic debris is found inland even in remote places like deserts (Zylstra, 2013). In aquatic environments, plastic has been found in rivers (Bakir et al., 2014; McCormick et al., 2014), lakes (Faure et al., 2015; Eriksen et al., 2013a), bays (Schlining et al., 2013), gulfs (Phillips and Bonner, 2015) and oceans (Eriksen et al., 2014). While the denser debris accumulates in rivers and estuarine sea floors (Schlining et al., 2013), buoyant plastic mostly ends up in open oceans (Jambeck et al., 2015) where, after being transported over long distances, buoyant plastic debris tends to converge in subtropical gyres (Moore, 2008).

The impact of plastic pollution in the oceans affects the whole ecosystem. The direct effects are entanglement and ingestion. Plastic fragmentation results in a continuum of debris sizes (ter Halle et al., 2016), leading to microscopic and even nanometric fragments (Gigault et al., 2016). Thus ingestion concerns both the larger animals, like cetaceans (Lusher et al., 2013; Lusher et al., 2015), turtles (Schuyler et al., 2012), sea birds (English et al., 2015; Ryan, 2015; Wilcox et al., 2015), and the smaller ones, like fishes (Collard et al., 2015); even zooplankton are concerned (Cole et al., 2013; Cole and Galloway, 2015). It has been demonstrated that plastic ingestion can significantly alter the feeding capacity and decrease the reproductive output of organisms (Cole et al., 2015). Another effect is the transportation of invasive species across oceans, which could potentially affect the equilibrium of ecosystems (Goldstein et al., 2014; Zettler et al., 2013). There are also toxic chemicals associated with plastic debris since the plastic contains additives, persistent organic pollutants and heavy metals (Rochman et al., 2013a). The transfer of these substances into the food web when plastic debris is ingested by animals has already been demonstrated for certain organisms (Rochman et al., 2014a; Rochman et al., 2014b; Rochman et al., 2013b; Tanaka et al., 2013; Wardrop et al., 2016).

Floating marine plastic debris converges in subtropical gyres (Law et al., 2010; Eriksen et al., 2013b; Goldstein et al., 2013; Van Sebille, 2015). Some convergence areas have been much more surveyed than others, e.g. the western North Atlantic Ocean (Law et al., 2010; MoretFerguson et al., 2010) and the eastern North Pacific Ocean (Goldstein et al., 2013; Law et al., 2014). The southern hemisphere has been studied far less (Eriksen et al., 2013b; Cozar et al., 2014). The vast

\footnotetext{
* Corresponding author.

E-mail address: ter-halle@chimie.ups-tlse.fr (A. ter Halle).
} 
majority of the sea surface has not been surveyed for plastic pollution and there is an evident lack of experimental measurements at sea. By means of circulation models, the weight of the global plastic debris floating at sea has been estimated at several hundred thousand metric tons (between 90,000 and 250,000 metric tons) (Cozar et al., 2014; van Sebille et al., 2015). These estimates correspond to only $1 \%$ of the global plastic waste input into the ocean in 2010 (Jambeck et al., 2015). There is an obvious need to better understand where plastic debris is located at sea. This is a crucial step toward assessing the severity of the impact of plastic pollution on marine life.

Because ocean motion is complex and variable, it is difficult to determine precisely the boundaries of subtropical gyres (Froyland et al., 2014) and we do not know, in real time, exactly where plastic particles are located and how they are distributed inside the accumulation areas. Simulations and models exist and are good indicators for a global approach (Eriksen et al., 2014; Maximenko et al., 2012; Lebreton et al., 2012). A recent article comparing existing models concluded that distributions of plastic within gyres were in relative agreement even if methods and inputs were different (van Sebille et al., 2015).

It has often been reported that the amount of plastic collected in trawls can show large variability, sometimes up to an order of magnitude within only a few tens of kilometers, but this has never been rationalized (van Sebille et al., 2015). Knowing that eddies (vortices of 50 to $200 \mathrm{~km}$ in diameter that are ubiquitous in the ocean) can trap and transport fluid parcels including nutrients, chlorophyll, and zooplankton (Flierl, 1981; Early et al., 2011; Chelton et al., 2011), we set out to test the hypothesis that plastic distribution at the sea surface could be partly attributed to the presence of eddies. Traditionally, the paradigm is that anticyclonic eddies (clockwise in the Northern Hemisphere) capture material drifting at the surface, while cyclonic eddies (anticlockwise in the Northern Hemisphere) tend to expel material (Chelton et al., 2011). However, the mechanisms are complex and some studies have shown that cyclonic eddies can also capture material very effectively (Froyland et al., 2014; Haller and Beron-Vera, 2013; BeronVera et al., 2016).

Satellites providing near-surface information on ocean physics and biology are the only practical means of obtaining dense, global observations of the open ocean. But the direct observation of plastic debris in oceans is not yet possible via satellites since methods like remote sensing cannot observe small particles of plastic directly because of the instrument resolution. Moreover, concentrations of microplastics are not high enough to modify the backscatter signal of the sea surface detectable by RADAR (used for monitoring hydrocarbon spills for instance). In this study, we propose to correlate satellite observations with in situ microplastic concentrations.

During the sea campaign Expedition 7th Continent in June 2015, we performed in situ measurements while navigating around and across two individual cyclonic (CE) and anticyclonic eddies (AE) in the North Atlantic gyre. The localization of the eddies was beforehand determined by current forecasts. This paper is organized as follows the in situ measurements have been correlated with SLA values, then thank to the use of an algorithm we identified structure coherent eddies in the area sampled and the plastic distribution was discussed with respect of these structures. The aim of this study is to rationalize in situ microplastic surface concentrations with the altimetry data and model surface currents that are available globally at daily resolution.

\section{Materials and methods}

\subsection{North Atlantic sea campaign routing}

The sea campaign Expedition 7th Continent took place in the western North Atlantic subtropical gyre between 15 and $30^{\circ} \mathrm{N}$ and 55 and $65^{\circ} \mathrm{W}$ from 28th May to 16th June 2015 (Fig. 1). The boat was guided day by day from Toulouse (France) using Copernicus Marine Environment Monitoring Service portal (CMEMS, http://marine.copernicus.

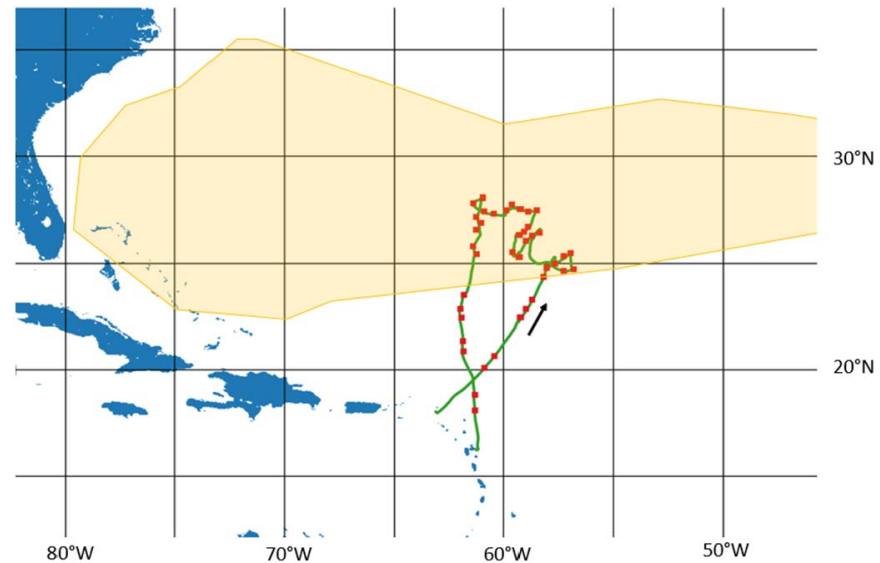

Fig. 1. Map of subtropical North-Western Atlantic Ocean. The route of the boat is represented by the green line, the red squares mark the location of each net tow and the yellow shading corresponds to the plastic accumulation area according to Lebreton et al. (Lebreton et al., 2012). (For interpretation of the references to colour in this figure legend, the reader is referred to the web version of this article.)

eu). The CMEMS data was referenced as GLOBAL_ANALYSIS_FORECAST_PHYS_001_002 (global ocean analysis and forecast model) and was available daily with a resolution of $1 / 12^{\circ}$. Our area of interest was mapped every day to forecast the following day's surface currents and sea surface height (SSH). In the area to be explored, SSH was between 3 and $40 \mathrm{~cm}$ and we planned to sample the whole range of SSH and to explore two mesoscale eddies. We tried to allocate sampling time evenly over the whole range of SSH but this was limited by logistical considerations, mainly the navigation speed and weather conditions.

\subsection{Net tow sampling}

On the sailing vessel Guyavoile, net tows were conducted using Neuston nets with a standard mesh size of $300 \mu \mathrm{m}$. Plastics were collected in a $0.5 \mathrm{~m} \times 0.4 \mathrm{~m}$ rectangular frame fitted with a $2 \mathrm{~m}$ long net. The net was equipped with a mechanical flow meter (Digital Flow Meter Model 438,110, Hydro-bios, Altenholz Germany), from which sea surface concentrations could be calculated and expressed as the number of pieces per square kilometer. The plastic debris was collected from the surface-layer at a depth of $0-20 \mathrm{~cm}$. Tow durations were set to $30 \mathrm{~min}$ and were all undertaken while the vessel was travelling at a speed of 1 to 2.5 knots. The wind speed was measured with an anemometer fixed on top of the mast at $27 \mathrm{~m}$. The Beaufort number was deduced from the wind speed measurements. The captain estimated the sea state of each sampling period. During this 17 -day long campaign, 41 nets were towed. The date, GPS location, Beaufort number and sea state for each net tow is reported in Table SI 1.

\subsection{Microplastics sorting, counting, weighing and preservation}

On the boat, the contents of the tows were filtered on $300 \mu \mathrm{m}$ sieves. Most of the plastic debris was removed with tweezers and stored at $-5{ }^{\circ} \mathrm{C}$ in glass vials. The remaining mixture of plankton and the smallest plastic debris was stored in flasks in a formol/sea water solution ( $5 \%$ vol formol) to preserve the plankton for identification and numbering. Under laboratory conditions and using a binocular microscope (magnification by 5 and 10), the small plastic debris was manually separated from natural matter with forceps. The remaining sample was inspected again on a glass plate. The plate was placed successively on top of white, black and red paper in order to sort out all the plastic debris. Sargassum was carefully inspected as plastic lines were often entangled in it. Microplastic is defined as plastic debris with a size below $5 \mathrm{~mm}$ (Arthur et al., 2009). In this study, plastic debris were sampled using a mesh size of $300 \mu \mathrm{m}$. All plastic debris was 
counted, including the mesoplastic $(5 \mathrm{~mm}-20 \mathrm{~cm})$. Mesoplastics represented about $10 \%$ in number of the debris collected. Plastic pieces were arranged in $20 \mathrm{~cm}$ diameter glass petri dishes according to their size and color (Fig. SI 1). Lines (the fibers were about $1 \mathrm{~mm}$ in diameter and were attributed to fishing lines because clothing fibers are typically thinner) were treated separately; they were measured manually with a ruler because they were often twisted. The petri dishes containing the pieces were scanned. The image was treated with ImageJ software. The pieces of plastic debris were individually identified and their length and width determined. Of the two dimensions established by ImageJ, the larger one was attributed to the length and the other to the width. All plastic debris were then weighed to the nearest $0.01 \mathrm{mg}$. Finally, they were stored individually in glass vials at $-18{ }^{\circ} \mathrm{C}$ for further characterization. The uncorrected sea surface concentrations of microplastics $\left(\mathrm{N}_{\text {tow }}\right)$ were expressed in number of pieces per square kilometer and are reported in Table SI 1.

\subsection{Surface concentrations correction}

The surface concentrations of microplastics were corrected in order to remove the variations induced by wind mixing $(\mathrm{N})$. We based our correction on the model described by Kukulka et al. (Kukulka et al., 2012) and an adjustment of the plastic debris rising velocity from Reisser et al. (Reisser et al., 2015). The detail of the correction is given in Section SI 1 and values are reported in Table SI 1. Reisser et al. compared the correction model with in situ measurements between 0 and $5 \mathrm{~m}$ below the surface and observed a good correlation at Beaufort between 1 and 4. Hence, all stations at Beaufort 5 were excluded from the discussion because the data were outside the limits of validity of the correction model. The mass concentrations were not corrected by the Kukulka model because the equations are based on the number of particles only.

\subsection{Sea level anomalies}

Sea level anomalies (SLA) are produced from satellite observations and, even if interpolation comes into play, these observations are much more precise than the SSH products from CMEMS used for routing the boat. Therefore SLA were used for the correlation with microplastic surface concentrations. We collected SLA observation products distributed by CMEMS portal and referenced as SEALEVEL_GLO_SLA_MAP_L4_REP_OBSERVATIONS_008_027. Data is produced by the Centre National d'Etudes Spatiales (CNES) in partnership with Collecte, Localisation, Satellites (CLS). Data is gridded and merged (interpolated from several satellites). Data is available daily and given with a formal mapping error of around $1 \mathrm{~cm}$ (depending on the location). The resolution is $14^{\circ}$. The SLA of the area explored were between -2.5 and $18 \mathrm{~cm}$ (details in Table SI 1). The SLA range was divided into three equal intervals: low $(-2.5$ to $5 \mathrm{~cm}$ ), medium (5 to $10 \mathrm{~cm}$ ) and high (10 to $18 \mathrm{~cm})$.

\subsection{Eddy identification}

Petersen et al.'s algorithm was used to detect and track the mesoscale eddies in the sampled area using the Okubo-Weiss (OW) parameter (Petersen et al., 2013). The OW parameter (W) is based on the velocity gradient tensor and highlights the flow part where vorticity dominates strain, which correspond to a negative parameter $\mathrm{W}$. This parameter was calculated from surface current data available from the CMEMS portal. This is a model product, referenced as GLOBAL_ANALYSIS_FORECAST_PHYS 001_002. It is available daily with a resolution of $1 / 12^{\circ}$. The algorithm made available on line by Petersen et al. (Petersen et al., 2013) was used and was adapted to the format of the present data files (NetCDF). W can be calculated over the whole globe but this parameter needs a threshold depending on the region of the ocean to identify the eddy edge $\left(\frac{W}{\sigma_{W}} \leq-0.2\right.$ is usually used, where $\sigma_{\mathrm{W}}$ is the standard deviation of $\mathrm{W}$ over the region of interest) (Petersen et al., 2013). We considered that translational motion of the eddy from east to west was negligible over the 15 days of the sampling period. We calculated the outlines of both eddies daily and defined their edges as the average over the 15 days.

\section{Results and discussion}

Microplastic surface concentrations will be either discussed uncorrected (Ntow expressed in pieces per square kilometer, Table SI 1), or corrected according to Kukulka model (N) (Kukulka et al., 2012). The uncorrected data are available in the supporting material section and the corrected data are presented in the article; most studies present corrected data (Cozar et al., 2014). Microplastic concentrations were typical of what is measured in the North Atlantic subtropical gyre (hundreds of thousands of pieces per square kilometer) (Law et al., 2010).

\subsection{Correlation with sea level anomalies}

During the sampling campaign, the explored area corresponded to SLA between $-2.5 \mathrm{~cm}$ and $+18 \mathrm{~cm}$ (Fig. 2). This range was divided into three equal intervals.

In total, we performed 41 measurements, 29 of which were within the subtropical gyre delimitated by Lebreton et al. (Lebreton et al., 2012). On average, microplastic abundance concentrations were 6.2 times higher inside the gyre than outside. In the subtropical gyre, microplastic corrected concentrations varied from 5000 to 360,000 pieces $/ \mathrm{km}^{2}$. The rest of the discussion concerns only the distribution of microplastics inside the subtropical gyre, where there were high variations (up to 70 fold). In spite of the dispersed values, $\mathrm{N}$ increased systematically with increasing SLA categories (Fig. 3). The uncorrected correlation with SLA is given in Fig. SI 2 and show the same tendency. The statistical Mann Whitney test at $5 \%$ indicated that microplastic concentrations were significantly different at low and high SLA (mean N at low SLA of 18,000 pieces $/ \mathrm{km}^{2}$ and 138,000 pieces/ $\mathrm{km}^{2}$. at high SLA, $p=1.3 \%$ ). Between these two categories, the mean $\mathrm{N}$ differed by a factor of 7.7 .

\subsection{Correlation with model currents}

In addition to investigating the correlation between the distribution of microplastics and SLA, the variations in local ocean circulation and

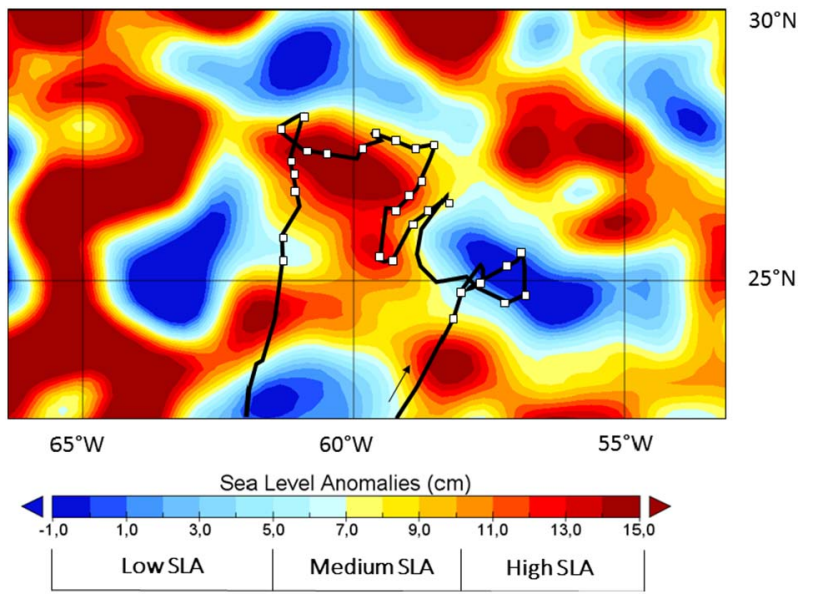

Fig. 2. Map of the sampled area within the North Atlantic subtropical gyre correlated with Sea Level Anomalies satellite observations obtained from the CMEMS portal (on 1st June 2015). The boat track is shown as a black line and was obtained by the Argos system; the sampling site locations are marked as white squares. 


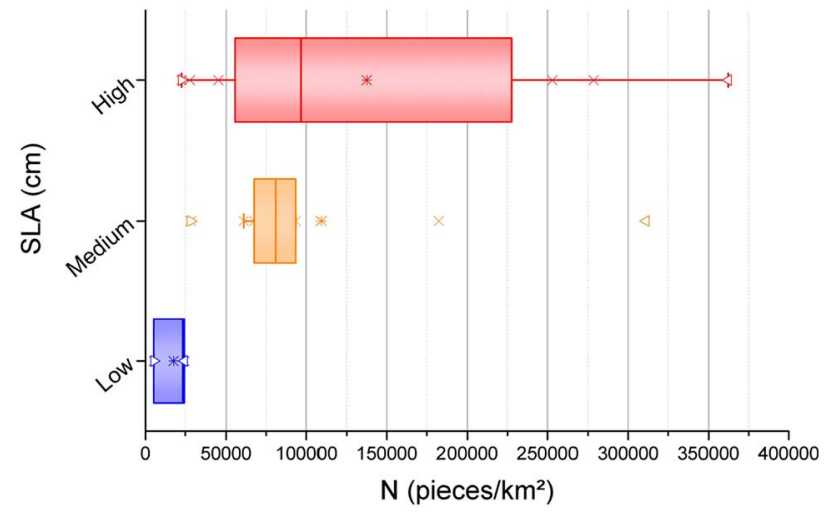

Fig. 3. Corrected sea surface concentrations of microplastics (N, pieces $\left./ \mathrm{km}^{2}\right)$ according to Sea Level Anomaly categories (SLA, cm). Whiskers correspond to 1.5 times the interquartile range. Values are represented by crosses, min. and max. values by triangles, and mean values by stars. This graph was obtained from 24 net tows ( 3 measurements at low SLA, 8 at medium and 13 at high SLA; 5 measurements at Beaufort 5 have been removed because of bad weather conditions).

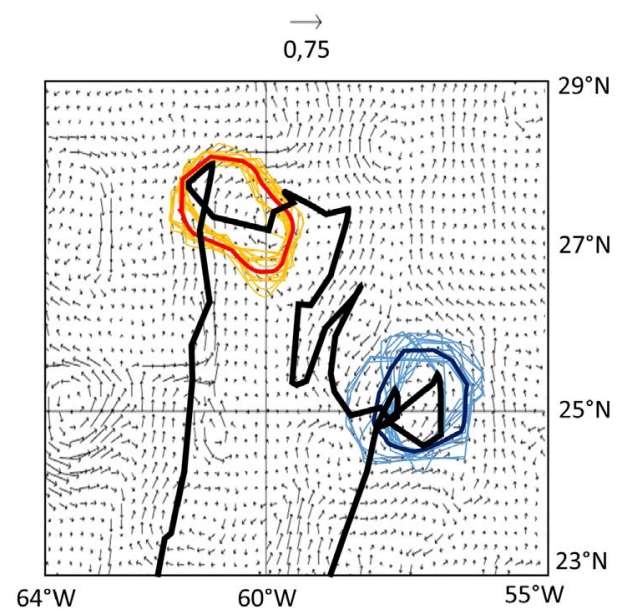

Fig. 4. Map representing the mean surface current vectors between 1 st and 15th June 2015, the boat track of the 7th Continent expedition is reported as a black line. The daily calculated eddy boundaries are represented by thin lines. In bold line was represented the average of the outlines calculated over 15 consecutive days. As the translational east-west motion of eddies was negligible over this time period, their boundaries were defined as the mean (bold line).

particularly mesoscale eddies will be discussed. Eddies are coherent mesoscale vortices of water that play a key role in the ocean. They have a dynamic influence in the ocean, especially on the transport of heat, salt, and water masses (Zhang et al., 2014; Faghmous et al., 2015). They also have a biological influence through upwelling of cold water rich in nutrients for the growth of phytoplankton or, on the contrary, downwelling (depending on the sense of rotation) (Zhang et al., 2014; Faghmous et al., 2015). There are various methods to identify eddies and determine their contour, using SLA is a first one, where the eddy boundaries are set to SLA above a given threshold (Fang and Morrow, 2003; Chaigneau and Pizarro, 2005). There are also methods based on the Okubo-Weiss (OW) parameter using velocity fields under vorticitydominated flows. We used this parameter and, as described in Fig. 4, the two eddies explored had well defined boundaries, which were determined by taking the average of the outlines found over 15 consecutive days. A movie showing the OW parameter over the 15 days of sampling is available in SI (Movie SI 1). Peterson et al. used a minimum lifetime cutoff of 28 days for well-defined eddies (Petersen et al., 2013). We ensured indeed that the two eddies explored had a lifetime well above that limit, they indeed already existed 6 months earlier (Fig. SI $3)$. In June 2015 , the cyclonic eddy was approximately $200 \mathrm{~km}$ by $150 \mathrm{~km}$ and the anticyclonic eddy was $200 \mathrm{~km}$ by $100 \mathrm{~km}$. The centers of the eddy were about $400 \mathrm{~km}$ apart. It took 5 days to sail from one eddy to the other under bad weather conditions. As expected, the eddy edges were correlated with SLA values (see Fig. SI 4) even though there was not a perfect match. This was principally due to a difference in resolution between the two data sets.

Microplastic surface concentrations were then compared within the two eddies (Fig. 5, for uncorrected data see Fig. SI 5). The mean $\mathrm{N}$ value in the cyclonic eddy was 20,000 pieces $/ \mathrm{km}^{2}$ compared to 170,000 pieces $/ \mathrm{km}^{2}$ in the anticyclonic eddy. The averaged microplastic surface concentration was 9.4 higher in the anticyclonic eddy. There is an important plastic concentration at the south east of the $\mathrm{AE}$ (Fig. 5), it is just at the limit of its boundaries and it illustrates the uncertainties of the mathematic delimitation of eddies edges. This measurement could have been included in the calculation of the ratio $\mathrm{AE} / \mathrm{CE}$ that would then equal 10.3. There was also significant plastic debris concentrations at the east of the $\mathrm{AE}$, it was located between two $\mathrm{AE}$ as can be seen in Fig. 2. There are very complicated turbulent effects at the eddies edges, convergence and divergence at small scale features could occur and influence plastic distribution at the surface. It would be very interesting to study these phenomenon in the future. In summary, from our in situ measurements, we observe that the anticyclonic eddy tended to accumulate more floating microplastic than the cyclonic eddy.

\section{Conclusion}

In conclusion, this study presents the first direct observation of different concentrations of plastic between a cyclonic and an anticyclonic mesoscale eddy. Although the sample size is small, the results here corroborate the hypothesis that mesoscale ocean dynamics impact plastic debris distribution at the sea surface within subtropical gyres. We strongly encourage further analysis of this effect in other trawl datasets. As anticyclonic eddies also tend to trap and transport
Eddies identified by OW

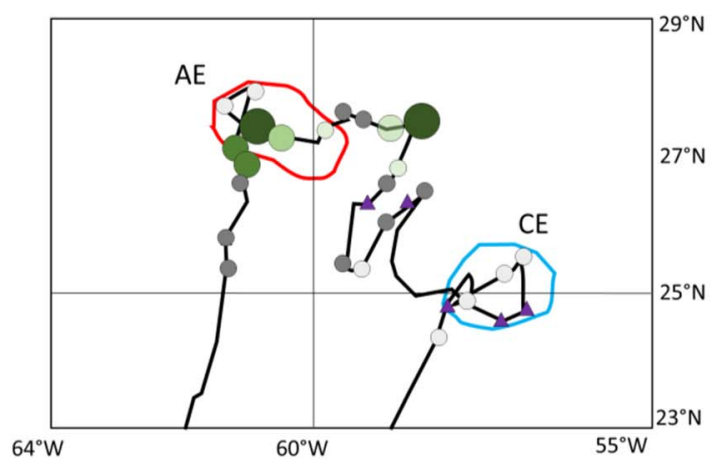

Fig. 5. Corrected surface microplastic concentrations (N) inside the gyre correlated with delimitation of eddies calculated using the Okubo-Weiss (OW) parameter. The route taken by the boat is shown as a black line, eddy boundaries are marked in blue and red for the cyclonic (3 measurements) and anticyclonic eddies (6 measurements), respectively. (For interpretation of the references to colour in this figure legend, the reader is referred to the web version of this article.) 
nutrients, chlorophyll and zooplankton, the environmental impact of plastic pollution should be considered from this perspective. Real-time surveys of the sea surface by space based instruments may therefore help to plan future campaigns with respect to the mesoscale convergence in eddies. Vortices in turbulence are often envisaged as rotating bodies of fluid, travelling as coherent islands in an incoherent ambient flow (Haller and Beron-Vera, 2013; Froyland et al., 2015) and it would be interesting to estimate the proportion of debris gathered and entrapped from the early stage of the eddy existence and the proportion of material captured and swallowed as the eddy travels eastwest inside the gyre. Of course, the leakage of material from eddies must also be considered. Finally, this study has only considered microplastics at the sea surface and the investigation of microplastics throughout the water column needs to be undertaken. As anticyclones are generally downwelling, how abundant would microplastic be at greater depths, especially at the core of eddies where the geostrophic speed is locally maximum at a certain depth (Chaigneau et al., 2011)?

Supplementary data to this article can be found online at https:// doi.org/10.1016/j.marpolbul.2017.10.077.

\section{Acknowledgments}

We thank the NGO Expedition 7th Continent for the logistic of the sea campaign and the NGO Ocean Science Logistic for building the manta nets. This research was funded by the CNES (151168/02) and by the Total Foundation. EvS was supported through funding from the European Research Council (ERC) under the European Union's Horizon 2020 research and innovation programme (grant agreement No 715386).

\section{References}

Arthur, C., Baker, J., Bamford, H., 2009. Proceedings of the International Research Workshop on the Occurrence, Effects, and Fate of Microplastic Marine Debris. (ed Program NMd).

Bakir, A., Rowland, S.J., Thompson, R.C., 2014. Transport of persistent organic pollutants by microplastics in estuarine conditions. Estuar. Coast. Shelf Sci. 140, 14-21.

Beron-Vera, F.J., Olascoaga, M.J., Lumpkin, R., 2016. Inertia-induced accumulation of flotsam in the subtropical gyres. Geophys Res. Lett. 43 (23), 12228-12233.

Chaigneau, A., Pizarro, O., 2005. Eddy characteristics in the eastern south pacific. J. Geophys. Res. Oceans 110 (C6) (C6005).

Chaigneau, A., Le Texier, M., Eldin, G., Grados, C., Pizarro, O., 2011. Vertical structure of mesoscale eddies in the eastern South Pacific Ocean: a composite analysis from altimetry and Argo profiling floats. J. Geophys. Res. Oceans 116.

Chelton, D.B., Gaube, P., Schlax, M.G., Early, J.J., Samelson, R.M., 2011. The influence of nonlinear mesoscale eddies on near-surface oceanic chlorophyll. Science 334 (6054), 328-332.

Cole, M., Galloway, T.S., 2015. Ingestion of nanoplastics and microplastics by pacific oyster larvae. Environ. Sci. Technol. 49 (24), 14625-14632.

Cole, M., Lindeque, P., Fileman, E., Halsband, C., Goodhead, R., Moger, J., Galloway, T.S., 2013. Microplastic ingestion by zooplankton. Environ. Sci. Technol. 47 (12) 6646-6655.

Cole, M., Lindeque, P., Fileman, E., Halsband, C., Galloway, T.S., 2015. The impact of polystyrene microplastics on feeding, function and fecundity in the marine copepod Calanus helgolandicus. Environ. Sci. Technol. 49 (2), 1130-1137.

Collard, F., Gilbert, B., Eppe, G., Parmentier, E., Das, K., 2015. Detection of anthropogenic particles in fish stomachs: an isolation method adapted to identification by Raman spectroscopy. Arch. Environ. Con. Toxicol 69 (3), 331-339.

Cozar, A., Echevarria, F., Gonzalez-Gordillo, J.I., Irigoien, X., Ubeda, B., Hernandez-Leon, S., Palma, A.T., Navarro, S., Garcia-de-Lomas, J., Ruiz, A., Fernandez-de-Puelles, M.L., Duarte, C.M., 2014. Plastic debris in the open ocean. Proc. Natl. Acad. Sci. U. S. A. 111 (28), 10239-10244.

Early, J.J., Samelson, R.M., Chelton, D.B., 2011. The evolution and propagation of quasigeostrophic ocean eddies. J. Phys. Oceanogr. 41 (8), 1535-1555.

English, M.D., Robertson, G.J., Avery-Gomm, S., Pine-Hay, D., Roul, S., Ryan, P.C., Wilhelm, S.I., Mallory, M.L., 2015. Plastic and metal ingestion in three species of coastal waterfowl wintering in Atlantic Canada. Mar. Pollut. Bull. 98 (1-2), 349-353.

Eriksen, M., Mason, S., Wilson, S., Box, C., Zellers, A., Edwards, W., Farley, H., Amato, S., 2013a. Microplastic pollution in the surface waters of the Laurentian Great Lakes. Mar. Pollut. Bull. 77 (1-2), 177-182.

Eriksen, M., Maximenko, N., Thiel, M., Cummins, A., Lattin, G., Wilson, S., Hafner, J., Zellers, A., Rifman, S., 2013b. Plastic pollution in the South Pacific subtropical gyre. Mar. Pollut. Bull. 68 (1-2), 71-76.

Eriksen, M., Lebreton, L.C.M., Carson, H.S., Thiel, M., Moore, C.J., Borerro, J.C., Galgani, F., Ryan, P.G., Reisser, J., 2014. Plastic pollution in the world's oceans: more than 5 trillion plastic pieces weighing over 250,000 tons afloat at sea. PLoS One 9 (12).
Faghmous, J.H., Frenger, I., Yao, Y.S., Warmka, R., Lindell, A., Kumar, V., 2015. A daily global mesoscale ocean eddy dataset from satellite altimetry. Sci. Data 2.

Fang, F.X., Morrow, R., 2003. Evolution, movement and decay of warm-core Leeuwin Current eddies. Deep Sea Res., Part II 50 (12 - 13), 2245-2261.

Faure, F., Demars, C., Wieser, O., Kunz, M., de Alencastro, L.F., 2015. Plastic pollution in Swiss surface waters: nature and concentrations, interaction with pollutants. Environ. Chem. 12 (5), 582-591.

Flierl, G.R., 1981. Particle motions in large-amplitude wave fields. Geophys. Astrophys. Fluid Dyn. 18 (1-2), 39-74.

Froyland, G., Stuart, R.M., van Sebille, E., 2014. How well-connected is the surface of the global ocean? Chaos 24 (3).

Froyland, G., Horenkamp, C., Rossi, V., van Sebille, E., 2015. Studying an Agulhas ring's long-term pathway and decay with finite-time coherent sets. Chaos 25 (8).

Gigault, J., Pedrono, B., Maxit, B., Ter Halle, A., 2016. Marine plastic litter: the unanalyzed nano-fraction. Environ. Sci. Nano 3 (2), 346-350.

Goldstein, M.C., Titmus, A.J., Ford, M., 2013. Scales of spatial heterogeneity of plastic marine debris in the Northeast Pacific Ocean. PLoS One 8 (11).

Goldstein, M.C., Carson, H.S., Eriksen, M., 2014. Relationship of diversity and habitat area in North Pacific plastic-associated rafting communities. Mar. Biol. 161 (6), 1441-1453.

ter Halle, A., Ladirat, L., Gendre, X., Goudouneche, D., Pusineri, C., Routaboul, C., Tenailleau, C., Duployer, B., Perez, E., 2016. Understanding the fragmentation pattern of marine plastic debris. Environ. Sci. Technol. 50 (11), 5668-5675.

Haller, G., Beron-Vera, F.J., 2013. Coherent Lagrangian vortices: the black holes of turbulence. J. Fluid Mech. 731.

Jambeck, J.R., Geyer, R., Wilcox, C., Siegler, T.R., Perryman, M., Andrady, A., Narayan, R., Law, K.L., 2015. Plastic waste inputs from land into the ocean. Science 347 (6223), 768-771.

Kukulka, T., Proskurowski, G., Moret-Ferguson, S., Meyer, D.W., Law, K.L., 2012. The effect of wind mixing on the vertical distribution of buoyant plastic debris. Geophys. Res. Lett. 39.

Law, K.L., Moret-Ferguson, S., Maximenko, N.A., Proskurowski, G., Peacock, E.E., Hafner, J., Reddy, C.M., 2010. Plastic accumulation in the North Atlantic subtropical Gyre. Science 329 (5996), 1185-1188.

Law, K.L., Moret-Ferguson, S.E., Goodwin, D.S., Zettler, E.R., De Force, E., Kukulka, T., Proskurowski, G., 2014. Distribution of surface plastic debris in the eastern Pacific Ocean from an 11-year data set. Environ. Sci. Technol. 48 (9), 4732-4738.

Lebreton, L.C.M., Greer, S.D., Borrero, J.C., 2012. Numerical modelling of floating debris in the world's oceans. Mar. Pollut. Bull. 64 (3), 653-661.

Lusher, A.L., McHugh, M., Thompson, R.C., 2013. Occurrence of microplastics in the gastrointestinal tract of pelagic and demersal fish from the English Channel. Mar. Pollut. Bull. 67 (1-2), 94-99.

Lusher, A.L., Hernandez-Millan, G., O'Brien, J., Berrow, S., 2015. Microplastic and macroplastic ingestion by a deep diving, oceanic cetacean: the true's beaked whale Mesoplodon mirus. Environ. Pollut. 199, 185-191.

Maximenko, N., Hafner, J., Niiler, P., 2012. Pathways of marine debris derived from trajectories of Lagrangian drifters. Mar. Pollut. Bull. 65 (1-3), 51-62.

McCormick, A., Hoellein, T.J., Mason, S.A., Schluep, J., Kelly, J.J., 2014. Microplastic is an abundant and distinct microbial habitat in an Urban River. Environ. Sci. Technol. 48 (20), 11863-11871.

Moore, C.J., 2008. Synthetic polymers in the marine environment: a rapidly increasing, long-term threat. Environ. Res. 108 (2), 131-139.

Moret-Ferguson, S., Law, K.L., Proskurowski, G., Murphy, E.K., Peacock, E.E., Reddy, C.M., 2010. The size, mass, and composition of plastic debris in the western North Atlantic Ocean. Mar. Pollut. Bull. 60 (10), 1873-1878.

Petersen, M.R., Williams, S.J., Maltrud, M.E., Hecht, M.W., Hamann, B., 2013. A threedimensional eddy census of a high-resolution global ocean simulation. J. Geophys. Res. Oceans 118 (4), 1759-1774.

Phillips, M.B., Bonner, T.H., 2015. Occurrence and amount of microplastic ingested by fishes in watersheds of the Gulf of Mexico. Mar. Pollut. Bull. 100 (1), 264-269.

Reisser, J., Slat, B., Noble, K., du Plessis, K., Epp, M., Proietti, M., de Sonneville, J. Becker, T., Pattiaratchi, C., 2015. The vertical distribution of buoyant plastics at sea: an observational study in the North Atlantic Gyre. Biogeosciences 12, 1249-1256.

Rochman, C.M., Browne, M.A., Halpern, B.S., Hentschel, B.T., Hoh, E., Karapanagioti, H.K., Rios-Mendoza, L.M., Takada, H., Teh, S., Thompson, R.C., 2013a. Classify plastic waste as hazardous. Nature 494 (7436), 169-171.

Rochman, C.M., Hoh, E., Kurobe, T., Teh, S.J., 2013b. Ingested plastic transfers hazardous chemicals to fish and induces hepatic stress. Sci Rep 3.

Rochman, C.M., Lewison, R.L., Eriksen, M., Allen, H., Cook, A.M., Teh, S.J., 2014a. Polybrominated diphenyl ethers (PBDEs) in fish tissue may be an indicator of plastic contamination in marine habitats. Sci. Total Environ. 476, 622-633.

Rochman, C.M., Kurobe, T., Flores, I., Teh, S.J., 2014b. Early warning signs of endocrine disruption in adult fish from the ingestion of polyethylene with and without sorbed chemical pollutants from the marine environment. Sci. Total Environ. 493, 656-661.

Ryan, P.G., 2015. How quickly do albatrosses and petrels digest plastic particles? Environ. Pollut. 207, 438-440.

Schlining, K., von Thun, S., Kuhnz, L., Schlining, B., Lundsten, L., Stout, N.J., Chaney, L., Connor, J., 2013. Debris in the deep: using a 22-year video annotation database to survey marine litter in Monterey canyon, central California, USA. Deep Sea Res. Part 1 Oceanogr. Res. Pap. 79, 96-105.

Schuyler, Q., Hardesty, B.D., Wilcox, C., Townsend, K., 2012. To eat or not to eat? Debris selectivity by marine turtles. PLoS One 7 (7).

van Sebille, E., Wilcox, C., Lebreton, L., Maximenko, N., Hardesty, B.D., van Franeker J.A., Eriksen, M., Siegel, D., Galgani, F., Law, K.L., 2015. A global inventory of small floating plastic debris. Environ. Res. Lett. 10 (12).

Tanaka, K., Takada, H., Yamashita, R., Mizukawa, K., Fukuwaka, M., Watanuki, Y., 2013. 
Accumulation of plastic-derived chemicals in tissues of seabirds ingesting marine plastics. Mar. Pollut. Bull. 69 (1-2), 219-222.

Van Sebille, E., 2015. The oceans' accumulating plastic garbage. Phys. Today 68 (2), 60-61.

Wardrop, P., Shimeta, J., Nugegoda, D., Morrison, P.D., Miranda, A., Tang, M., Clarke, B.O., 2016. Chemical pollutants sorbed to ingested microbeads from personal care products accumulate in fish. Environ. Sci. Technol. 50 (7), 4037-4044.

Wilcox, C., Van Sebille, E., Hardesty, B.D., 2015. Threat of plastic pollution to seabirds is global, pervasive, and increasing. Proc. Natl. Acad. Sci. U. S. A. 112 (38)

11899-11904.

Zettler, E.R., Mincer, T.J., Amaral-Zettler, L.A., 2013. Life in the "Plastisphere": microbial communities on plastic marine debris. Environ. Sci. Technol. 47 (13), 7137-7146. Zhang, Z.G., Wang, W., Qiu, B., 2014. Oceanic mass transport by mesoscale eddies. Science 345 (6194), 322-324.

Zylstra, E.R., 2013. Accumulation of wind-dispersed trash in desert environments. J. Arid Environ. 89, 13-15. 